\title{
Instrumentos para la valoración de las necesidades de los familiares de pacientes ingresados en cuidados intensivos: una revisión sistemática
}

\author{
Instruments for the assessment of the needs of family \\ members of patients in intensive care units: \\ a systematic review
}

\author{
M. Olano, C.G. Vivar
}

\begin{abstract}
RESUMEN
El ingreso de un familiar en una unidad de cuidados intensivos es un evento estresante para los miembros de la familia. Durante ese periodo, la familia padece situaciones de miedo, incertidumbre y cansancio, y dedica toda su atención a la evolución del familiar ingresado. En ese contexto, resulta imprescindible el apoyo y la atención por parte de los profesionales sanitarios mediante la valoración de las necesidades propias de la familia. Existen diversos instrumentos creados para la valoración de dichas necesidades. A través de esta revisión sistemática, se pretende identificar cuáles son esos cuestionarios y analizar críticamente sus características para ofrecer a los profesionales que trabajan en áreas de críticos unos cuestionarios válidos y fiables que puedan utilizar en el abordaje a las familias.
\end{abstract}

Palabras clave. Familia. Necesidades. Unidad de Cuidados Intensivos. Cuestionario.

\begin{abstract}
The hospitalisation of a family member in an intensive care unit is a stressful event for the rest of the family members. During hospitalisation, the family suffers situations of fear, uncertainty and tiredness, and focuses on the medical evolution of their ill member. In this context, support and attention from health care professionals through the assessment of the needs of the family are crucial. There are different instruments for the assessment of a family's needs. This systematic review aims to identify these questionnaires and to critically analyse their characteristics, so as to offer professionals valid and reliable questionnaires that they can use when caring for families in critical units.
\end{abstract}

Keywords. Family. Needs. Intensive Care Unit. Questionnaire.
Universidad de Navarra.

Facultad de Enfermería

Recepción: 6 de agosto de 2011

Aceptación provisional: 14 de octubre de 2011

Aceptación definitiva: 14 de diciembre de 2011

\section{Correspondencia:}

Maddi Olano Lizarraga

C/ Irunlarrea, 1

31008 Pamplona

Facultad de Enfermería. Universidad de Navarra Pamplona

E-mail: molizarraga@unav.es 


\section{INTRODUCCIÓN}

Cuando un paciente ingresa en una unidad de cuidados intensivos (UCI) la mayoría de las veces es de manera inesperada. En estas circunstancias, los familiares de esa persona no están preparados psicológicamente para ese evento y pueden tener reacciones emocionales como el miedo, la frustración o la culpa ${ }^{1}$. La UCI es un lugar estresante para las familias ${ }^{2,3}$ y puede provocar ansiedad y situaciones de crisis ${ }^{4}$ que pueden llevar a la alteración de los roles familiares, a la desorganización y a la fragmentación familiar ${ }^{5}$. Según Fuertes y $\mathrm{Maya}^{6}$, el proceso de enfermedad requiere una adaptación de toda la familia a la nueva situación y puede desencadenar situaciones de conflicto e incluso enfermedad en otros miembros de la familia, ya que se incrementa el riesgo de que no atiendan sus propias necesidades, manifestando comportamientos no saludables como descanso inadecuado, falta de ejercicio o dieta po$\mathrm{bre}^{7}$. Partiendo de estas premisas, se puede afirmar que las familias no son meros visitantes en el entorno de la UCI, sino que son una extensión del paciente y experimentan el proceso de cuidado al lado de éste . $^{8}$.

Entre las necesidades que se consideran más importantes para las familias, destacan las de seguridad, información, proximidad, apoyo y confort ${ }^{9,10}$. Las intervenciones de los profesionales sanitarios que detectan estas necesidades facilitan que la familia se adapte a la situación de transición ${ }^{11}$. Sin embargo, algunos profesionales no son suficientemente conscientes de las necesidades de las familias ${ }^{12}$ o si lo son, la falta de tiempo $^{13}$ o de conocimientos ${ }^{14}$ les limita. Por ello, a pesar de que múltiples estudios de investigación han identificado las necesidades de los familiares de UCI, los resultados no son siempre utilizados para guiar la práctica ${ }^{15}$.

Un enfoque holístico en el cuidado a la persona, requiere que los profesionales evalúen las necesidades con herramientas válidas y fiables, desarrollen estrategias de intervención y programas de asesoramiento para satisfacer las necesidades identificadas $^{16,17}$. Este conocimiento es esencial para optimizar el bienestar y el afrontamiento de las familias, ya que así, ellos podrán proporcionar un apoyo apropiado a sus familiares hospitalizados $^{16}$. Los profesionales sanitarios deben extender su práctica y cuidar al paciente y a la familia como unidad ${ }^{18}$. Este enfoque, puede ayudar a que los sanitarios comprendan mejor la situación de la familia y a que promocionen su salud ${ }^{19}$. Las intervenciones educativas, deben basarse en las percepciones de las familias sobre sus necesidades ${ }^{20-22}$ y por esta razón, resulta imprescindible realizar una valoración individualizada que permita adecuar la atención a cada situación.

Esta revisión tiene dos objetivos principales. El primero es conocer y examinar las características de los instrumentos válidos y fiables existentes para valorar las necesidades de los familiares de pacientes ingresados en una UCI, y poder así determinar cuáles se pueden aplicar de modo estandarizado en la atención a las familias. El segundo objetivo es analizar los estudios que han utilizado los citados instrumentos, valorando su objetivo, su calidad y sus resultados.

\section{METODOLOGÍA}

Para lograr los objetivos de este estudio, se realizó una revisión sistemática que recopila la mejor evidencia disponible ${ }^{23}$. Antes de iniciar la búsqueda, se definieron los criterios de inclusión y exclusión (Tabla 1).

La búsqueda bibliográfica se realizó entre marzo y abril de 2011 y se utilizaron las bases de datos CINAHL, Cochrane Library, CUIDEN, Medline y PsycINFO. Se manejaron las citadas fuentes para explorar ampliamente la evidencia existente sobre el tema seleccionado. Así, primeramente se descartó que hubiese revisiones sistemáticas sobre el tema comprobándolo en las mencionadas bases de datos. Después, se utilizó una base de datos extensa y multidisciplinar como Medline para llegar a la realidad desde diversas perspectivas sanitarias. Asimismo, se recurrió a herramientas específicas del ámbito de la enfermería como CINAHL y CUIDEN, además de realizar una búsqueda en PsycINFO por tratarse de una área ampliamente estudiada desde la perspectiva psicológica. 
Tabla 1. Criterios de inclusión y exclusión

\begin{tabular}{|c|c|}
\hline Criterios de inclusión & Criterios de exclusión \\
\hline Estudios con pacientes y familiares adultos & Pacientes pediátricos y familiares menores de edad \\
\hline $\begin{array}{l}\text { Valoración cuantitativa de las necesidades de los } \\
\text { familiares durante el ingreso en la UCI }\end{array}$ & $\begin{array}{l}\text { Familiares de pacientes ingresados en otras unidades } \\
\text { que no sean la UCI }\end{array}$ \\
\hline Idioma: español e inglés & $\begin{array}{l}\text { Estudios que exploran las necesidades de los pacientes } \\
\text { ingresados }\end{array}$ \\
\hline $\begin{array}{l}\text { Investigaciones primarias, revisiones bibliográficas o } \\
\text { tesis doctorales }\end{array}$ & $\begin{array}{l}\text { Valoraciones de las necesidades de las familias } \\
\text { mediante estudios cualitativos }\end{array}$ \\
\hline Artículos con acceso al resumen y al texto completo & $\begin{array}{l}\text { Literatura gris (folletos, editoriales, artículos de } \\
\text { opinión...), exceptuando tesis doctorales }\end{array}$ \\
\hline $\begin{array}{l}\text { Para ello, se analizó la pregunta siguien- } \\
\text { do la estrategia PICO (Population-Interven- } \\
\text { tion-Comparison-Outcome, o Población-In- } \\
\text { tervención-Âmbito-Resultado), que ayuda } \\
\text { a focalizar la pregunta, identificar los estu- } \\
\text { dios relacionados y proporcionar un méto- } \\
\text { do de análisis de la pregunta sistemático y }\end{array}$ & $\begin{array}{l}\text { fácil de aplicar }{ }^{24} \text {. En la búsqueda se combi- } \\
\text { naron términos traducidos al inglés e iden- } \\
\text { tificados de la literatura, del Tesauro y de } \\
\text { los términos MeSH, utilizando operadores } \\
\text { booleanos y truncando palabras para in- } \\
\text { cluir posibles variaciones utilizadas en la } \\
\text { literatura (Fig. 1). }\end{array}$ \\
\hline
\end{tabular}

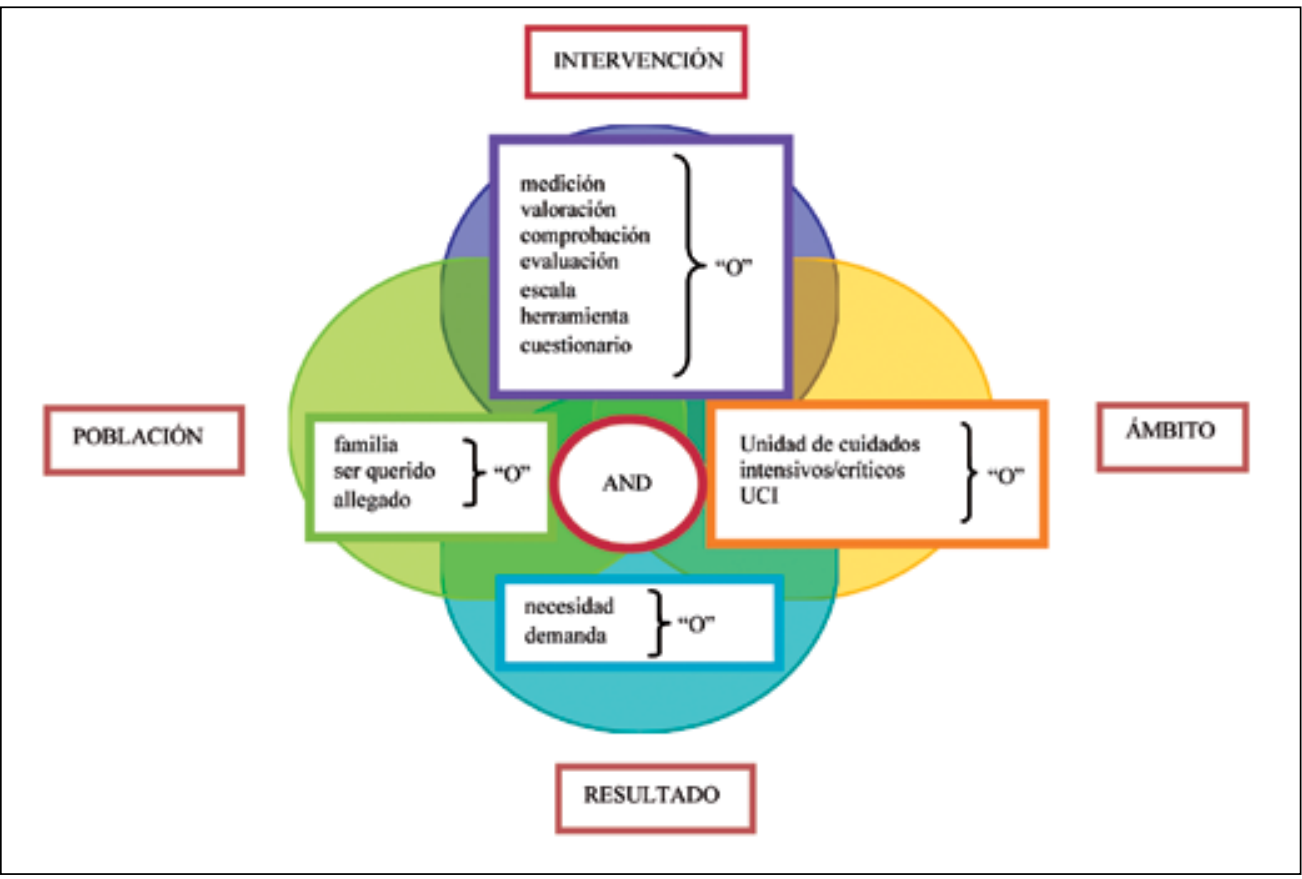

Figura 1. Estrategia PICO: Análisis de la pregunta y palabras clave de la búsqueda.

De acuerdo a los criterios de selección establecidos, se aplicaron varios límites en las bases de datos, restringiendo los resultados a publicaciones escritas en inglés o español, a participantes adultos y a documentos con acceso al resumen y al texto completo. Se optó por no ceñir la búsqueda a un intervalo de tiempo, puesto que las 
investigaciones acerca de las necesidades de los familiares en las UCIs tuvieron su inicio en la década de los 70 y aunque algunos estudios pudiesen resultar antiguos, son considerados imprescindibles en el mencionado ámbito. Además, para verificar la existencia de artículos adicionales, se realizaron búsquedas con la técnica bola de nieve (snowballing), y se seleccionaron varios artículos más.

Se identificaron 59 publicaciones que tras la lectura del título y el resumen podrían cumplir los criterios de inclusión.
Tras la lectura completa de los textos, se determinó que 40 artículos cumplían los criterios de inclusión, procediendo a evaluar su calidad metodológica. Una vez valorada la calidad de los artículos, 30 obtuvieron como resultado una calidad media o alta y 10 fueron calificados de calidad baja por presentar falta de validez interna, al tratarse de estudios que se habían basado en cuestionarios no validados, y por tanto no se incluyeron en la revisión. En la figura 2 se presenta la secuencia completa de la estrategia de búsqueda utilizada.

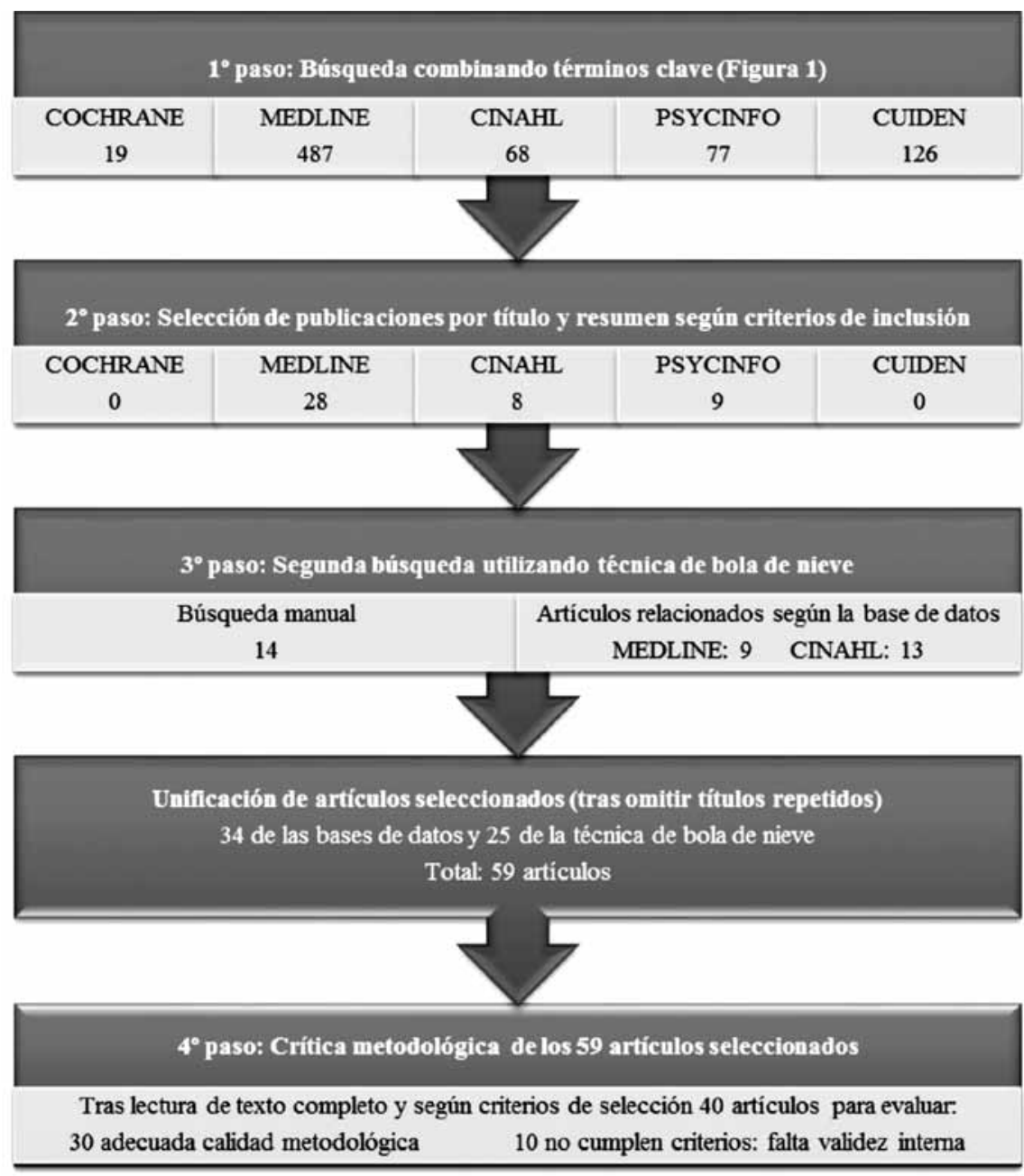

Figura 2. Resultado de la estrategia de búsqueda. 
A pesar de no haber realizado una revisión por pares para evaluar la relevancia de los estudios incluidos en este artículo, destacamos la rigurosa estrategia de búsqueda realizada así como el proceso sistemático de selección y análisis de los estudios. Para evaluar la calidad de los estudios, utilizamos como referencia los criterios de validez metodológica de las siguientes tres herramientas: Scottish Intercollegiate Guidelines Network $^{25}$, Critical Appraisal Skills Programme Español ${ }^{26}$ y el instrumento propuesto por Berra y $\mathrm{col}^{27}$ para la lectura crítica y la evaluación de estudios transversales.

\section{RESULTADOS DE LA BÚSQUEDA Instrumentos identificados y sus características}

Se encontraron cinco cuestionarios que se emplean para valorar las necesidades de los familiares de pacientes de UCI: CCFNI (Critical Care Family Needs Inventory), FS-ICU (Family Satisfaction in the Intensive Care Unit), SCCMFNA (Society of Critical Care Medicine's Family Needs Assessment), Family Satisfaction Survey y CCFSS (Critical Care Family Satisfaction Survey).

En la tabla 2 están resumidas las características de los cinco cuestionarios revisados y en la misma tabla se identifican las categorías de necesidades que se exploran en cada cuestionario.

\section{Análisis de los estudios}

De los 30 estudios incluidos en la revisión: uno es un estudio cuasi-experimental $^{20}$, uno es un ensayo no controlado ${ }^{30}, 3$ son revisiones bibliográficas ${ }^{32-34}$, uno es un estudio con triangulación múltiple ${ }^{35}$, uno es un estudio con metodología combinada de tipo explicatorio ${ }^{36}, 3$ son observacionales correlacionales transversales ${ }^{29,31,37}$, uno es un estudio observacional comparativo longitudinal $^{38}, 2$ son estudios observacionales comparativos transversales ${ }^{39,40}$ y 17 son estudios observacionales descriptivos transversales $^{5,11,16,17,21,22,28,41-50}$.

En la tabla 3 se adjunta la lista de los artículos incluidos, señalando el objetivo del estudio, el tipo de estudio y el nivel de evidencia que aporta, la muestra utilizada, el cuestionario utilizado y los resultados de mayor interés.
El cuestionario CCFNI es el más utilizado desde su creación, pero es posible criticar su desarrollo, ya que no está claro por qué Molter ${ }^{28}$ utilizó a estudiantes de enfermería en su creación. Además, tratándose de la primera vez que se aplicaba el cuestionario, podía haber preguntado a los participantes si ellos añadirían alguna necesidad más de las contempladas o si creían que sus necesidades estaban cubiertas o iban a poder serlo.

A pesar de esto, fue uno de los primeros estudios que reconoció la importancia de satisfacer las necesidades de los familiares y desde su creación ha sido replicado en múltiples estudios en varios países $^{9,11,16,17,20-22,35-41,44,46,50}$, utilizando versiones modificadas y obteniendo una adecuada fiabilidad y validez del instrumento. Es más, las revisiones bibliográficas analizadas $^{32-34}$ lo identifican como el instrumento más utilizado en el ámbito.

La mayoría de los estudios realizados con este cuestionario, son meramente descriptivos. Solamente el de Chien y $\mathrm{col}^{20}$, que es un estudio cuasi experimental (no hay aleatorización de los grupos), trata de examinar el efecto de un programa de educación basado en necesidades. La intervención se realiza al grupo experimental en el segundo y tercer día tras el ingreso y consta de dos sesiones de una hora en las que una enfermera instruida lleva a cabo reuniones educativas basadas en los resultados del CCFNI de los participantes y en resultados de estudios similares. Igualmente, se les entrega un folleto informativo sobre aspectos clave de la UCI y se realiza un seguimiento telefónico diario para informar a los familiares sobre los cambios que se han producido en la evolución del paciente y preguntarles sobre sus preocupaciones. Tras la intervención, los investigadores comprueban que en el grupo experimental ha habido un incremento estadísticamente significativo en la satisfacción de las necesidades y una disminución de la ansiedad (medido a través de la escala STAI State-Trait Anxiety Inventory). Sin embargo, la aplicación de este estudio puede verse limitada por tener una muestra pequeña y de conveniencia (32 familiares en el grupo control y 34 en el de intervención). 
Tabla 2. Resumen de los cuestionarios que valoran las necesidades de las familias de pacientes de UCI

\begin{tabular}{|c|c|c|c|c|c|c|}
\hline & \multirow{2}{*}{ Características } & \multicolumn{5}{|c|}{ Cuestionarios } \\
\hline & & CCFNI & FS-ICU & SCCMFNA & $\begin{array}{c}\text { Family Satisfaction } \\
\text { Survey }\end{array}$ & CCFSS \\
\hline & Autor & Molter $^{28}(1979)$ & $\begin{array}{c}\text { Heyland y } \\
\text { Tranmer }^{29}(2001)\end{array}$ & $\begin{array}{l}\text { Society of Critical } \\
\text { Care Medicine } \\
\text { (1993), modificado } \\
\text { por Johnson y } \text { col }^{5} \\
\text { (1998) }\end{array}$ & $\begin{array}{c}\text { Dowling y } \\
{\text { col } .{ }^{30}(2005) \text { en }} \text { colaboración } \\
\text { con Critical Care } \\
\text { Family Assistance } \\
\text { Program (CCFAP) }\end{array}$ & $\begin{array}{l}\text { Wasser y col. }{ }^{31} \\
\text { (2001) }\end{array}$ \\
\hline & Marco teórico & $\begin{array}{c}\text { Revisión de la } \\
\text { literatura y encuesta } \\
\text { a } 23 \text { estudiantes } \\
\text { enfermería }\end{array}$ & $\begin{array}{c}\text { Satisfacción del } \\
\text { paciente, calidad } \\
\text { del cuidado al } \\
\text { final de la vida, } \\
\text { investigaciones } \\
\text { sobre necesidades } \\
\text { de familiares de } \\
\text { pacientes críticos, } \\
\text { literatura sobre } \\
\text { (in)satisfacción de } \\
\text { familias con toma } \\
\text { de decisiones y } \\
\text { valoración de } 16 \\
\text { profesionales y } 21 \\
\text { familiares }\end{array}$ & $\begin{array}{c}\text { Basado en } \\
\text { un proyecto } \\
\text { que incluía } \\
\text { percepciones } \\
\text { de familiares de } \\
\text { UCI sobre cómo } \\
\text { habían sido } \\
\text { satisfechas sus } \\
\text { necesidades antes } \\
\text { y después de } \\
\text { la introducción } \\
\text { de un grupo de } \\
\text { voluntarios en las } \\
\text { salas de espera } \\
\text { de UCI }\end{array}$ & $\begin{array}{c}\text { Basado en el } \\
\text { cuestionario de } \\
\text { Heyland } y \text { col. } .^{35} \\
\text { (2002) }\end{array}$ & $\begin{array}{l}37 \text { cuestiones } \\
\text { de la literatura } \\
\text { y de aspectos } \\
\text { que detectan } \\
\text { la satisfacción } \\
\text { con el cuidado } \\
\text { del paciente. } \\
\text { Después pidieron } \\
\text { a profesionales } \\
\text { sanitarios que los } \\
\text { clasificaran en } \\
\text { subescalas }\end{array}$ \\
\hline & Propósito & $\begin{array}{l}\text { Conocer el grado } \\
\text { de importancia de } \\
\text { las necesidades de } \\
\text { familias de UCI } \\
\text { Proporcionar } \\
\text { un instrumento } \\
\text { para abarcar una } \\
\text { amplia gama de } \\
\text { necesidades } \\
\text { Facilitar un } \\
\text { instrumento } \\
\text { práctico y útil para } \\
\text { la práctica clínica }\end{array}$ & $\begin{array}{c}\text { Desarrollar una } \\
\text { herramienta para } \\
\text { medir el nivel } \\
\text { de satisfacción } \\
\text { de miembros de } \\
\text { familias con el } \\
\text { cuidado recibido } \\
\text { por ellos y } \\
\text { por su familiar } \\
\text { críticamente } \\
\text { enfermo }\end{array}$ & $\begin{array}{c}\text { Medir la } \\
\text { capacidad de } \\
\text { satisfacer las } \\
\text { necesidades de } \\
\text { las familias en } \\
\text { la UCI }\end{array}$ & $\begin{array}{l}\text { Responder a } \\
\text { necesidades } \\
\text { no satisfechas } \\
\text { de familias } \\
\text { de pacientes } \\
\text { ingresados en } \\
\text { UCI a través } \\
\text { de la provisión } \\
\text { de recursos } \\
\text { educativos y } \\
\text { apoyo familiar }\end{array}$ & $\begin{array}{c}\text { Desarrollar } \\
\text { instrumento } \\
\text { para medir la } \\
\text { satisfacción } \\
\text { de miembros } \\
\text { de la familia } \\
\text { de pacientes } \\
\text { ingresados en UCI }\end{array}$ \\
\hline \multirow{9}{*}{ 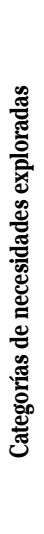 } & Seguridad & $\boldsymbol{\Delta}$ & & & $\Delta$ & $\boldsymbol{\Delta}$ \\
\hline & Información & $\boldsymbol{\Delta}$ & $\Delta$ & $\boldsymbol{\Delta}$ & $\Delta$ & $\boldsymbol{\Delta}$ \\
\hline & Proximidad & $\Delta$ & & & & $\Delta$ \\
\hline & Apoyo & $\boldsymbol{\Delta}$ & & $\boldsymbol{\Delta}$ & $\Delta$ & $\boldsymbol{\Delta}$ \\
\hline & Confort & $\Delta$ & $\Delta$ & $\Delta$ & $\Delta$ & $\boldsymbol{\Delta}$ \\
\hline & Toma de decisiones & & $\Delta$ & & & \\
\hline & Cuidado al paciente & & $\Delta$ & & & \\
\hline & $\begin{array}{c}\text { Cualidades del } \\
\text { profesional }\end{array}$ & & $\boldsymbol{\Delta}$ & $\boldsymbol{\Delta}$ & $\boldsymbol{\Delta}$ & \\
\hline & $\begin{array}{l}\text { Satisfacción general } \\
\text { con la atención }\end{array}$ & & $\Delta$ & & $\boldsymbol{\Delta}$ & \\
\hline
\end{tabular}




\begin{tabular}{|c|c|c|c|c|c|}
\hline \multirow{2}{*}{ Características } & \multicolumn{5}{|c|}{ Cuestionarios } \\
\hline & CCFNI & FS-ICU & SCCMFNA & $\begin{array}{c}\text { Family Satisfaction } \\
\text { Survey }\end{array}$ & CCFSS \\
\hline Modo de completarlo & Autoadministrado & Autoadministrado & Autoadministrado & Autoadministrado & Autoadministrado \\
\hline Extensión & 45 ítems & 34 ítems & 14 ítems & 15 ítems & 20 ítems \\
\hline $\begin{array}{l}\text { Unidad de análisis del } \\
\text { instrumento }\end{array}$ & Un único familiar & Un único familiar & Un único familiar & Un único familiar & Un único familiar \\
\hline Sistema de puntuación & $\begin{array}{l}\text { Escala tipo Likert, } \\
\text { graduada en } 4 \\
\text { puntos, desde el } 1 \\
\text { o "no importante" } \\
\text { hasta el } 4 \text { o "muy } \\
\text { importante" }\end{array}$ & $\begin{array}{l}\text { Excelente (100 } \\
\text { puntos), muy } \\
\text { bien (75), bien } \\
\text { (50) y escaso/ } \\
\text { malo (0) } \\
\text { Sí (100 puntos) y } \\
\text { No (0 puntos) }\end{array}$ & $\begin{array}{l}\text { Del } 1 \text { al } 4 \text { según } \\
\text { "satisfacción } \\
\text { extrema" o } \\
\text { "insatisfacción } \\
\text { extrema" } \\
\text { respectivamente; } \\
\text { puntuación final } \\
\text { con la suma de } \\
\text { todos los puntos; } \\
\text { puntuación } \\
\text { mínima } 14 \text { (la } \\
\text { más satisfactoria) } \\
\text { y } 56 \text { (la menos } \\
\text { deseada) }\end{array}$ & $\begin{array}{l}\text { Desde } 1 \text { (muy } \\
\text { escaso) hasta } 5 \\
\text { (muy bien) }\end{array}$ & $\begin{array}{c}\text { Del } 5 \text { al } 1 \text {, desde } \\
\text { "muy satisfecho" } \\
\text { hasta "muy } \\
\text { insatisfecho"; se } \\
\text { tiene en cuenta } \\
\text { el número de } \\
\text { apartados de } \\
\text { cada subescala } \\
\text { a la hora de } \\
\text { compararlas }\end{array}$ \\
\hline Fiabilidad & $\begin{array}{c}\text { Homogeneidad: } \\
\text { consistencia } \\
\text { interna: } \mathrm{r}=0,92 \\
\\
\text { Estabilidad: } \\
64,71-96,08 \%\end{array}$ & $\begin{array}{c}\text { Homogeneidad: } \\
\text { consistencia } \\
\text { interna: } r=0,847\end{array}$ & $\begin{array}{l}\text { (Dicen que está } \\
\text { confirmada pero } \\
\text { no dan datos) }\end{array}$ & $\begin{array}{l}\text { Evaluado por el } \\
\text { equipo (no dan } \\
\text { datos) }\end{array}$ & $\begin{array}{c}\text { Homogeneidad: } \\
\text { consistencia } \\
\text { interna: } r=0,67 \\
\text { Estabilidad: } \\
74,2-83,3 \%\end{array}$ \\
\hline Validez & $\begin{array}{l}\alpha=0,61-0,88 \\
\text { Correlación: } \\
r=0,07-0,39\end{array}$ & $\begin{array}{c}\alpha=0,74-0,97 \\
\text { Correlación: } \\
r=0,636\end{array}$ & $\alpha=0,76$ & $\alpha=0,75-0,94$ & $\begin{array}{c}\alpha=0,91 \\
\text { Correlación: } \\
r=0,75\end{array}$ \\
\hline Crítica & $\begin{array}{l}\text { Valora a un único } \\
\text { miembro } \\
\begin{array}{c}\text { Respuestas rígidas } \\
\text { (falta una pregunta } \\
\text { abierta) }\end{array} \\
\text { No aborda aspectos } \\
\text { emocionales } \\
\text { Extenso }\end{array}$ & $\begin{array}{l}\text { Valora a un único } \\
\text { miembro } \\
\text { Respuestas } \\
\text { rígidas (falta una } \\
\text { pregunta abierta) } \\
\text { No aborda } \\
\text { aspectos } \\
\text { emocionales } \\
\text { Extenso } \\
\text { No valora todas } \\
\text { las necesidades } \\
\text { importantes }\end{array}$ & $\begin{array}{l}\text { Valora a un único } \\
\text { miembro } \\
\text { Respuestas } \\
\text { rígidas (falta una } \\
\text { pregunta abierta) } \\
\text { No aborda } \\
\text { aspectos } \\
\text { emocionales } \\
\text { No valora todas } \\
\text { las necesidades } \\
\text { importantes }\end{array}$ & $\begin{array}{l}\text { Valora a un único } \\
\text { miembro } \\
\text { Respuestas } \\
\text { rígidas (falta una } \\
\text { pregunta abierta) } \\
\text { No aborda } \\
\text { aspectos } \\
\text { emocionales } \\
\text { Valoración } \\
\text { limitada de las } \\
\text { necesidades }\end{array}$ & $\begin{array}{c}\text { Valora a un único } \\
\text { miembro } \\
\text { Respuestas } \\
\text { rígidas (falta una } \\
\text { pregunta abierta) } \\
\text { No aborda } \\
\text { aspectos } \\
\text { emocionales } \\
\text { Respuestas } \\
\text { demasiado } \\
\text { relacionadas } \\
\text { con aspectos del } \\
\text { paciente }\end{array}$ \\
\hline
\end{tabular}

Por otro lado, varios estudios ${ }^{17,22,37,46,50}$ utilizan aparte del CCFNI, el cuestionario NMI (Needs Met Inventory). Esta escala difiere de la anterior en que en este caso, el investigador pide al familiar que ordene los mismos ítems según la percepción que tiene sobre si las necesidades están sien- do satisfechas, en vez de según el orden de importancia que les da. Asociar estas dos evaluaciones puede resultar útil para comprobar en qué medida se están incorporando cambios en la atención según las necesidades detectadas. 
Tabla 3. Resultado de los estudios incluidos en la revisión.

\begin{tabular}{|c|c|c|c|c|c|}
\hline $\begin{array}{l}\text { Autor } \\
\text { (año) }\end{array}$ & Objetivo & $\begin{array}{l}\text { Tipo de estudio } \\
\text { y nivel de } \\
\text { evidencia }\end{array}$ & $\begin{array}{l}\text { Muestra de } \\
\text { familiares }\end{array}$ & $\begin{array}{c}\text { Cuestionario } \\
\text { utilizado para } \\
\text { valorar las } \\
\text { necesidades }\end{array}$ & Resultados de interés \\
\hline $\begin{array}{l}\text { Al- } \\
\text { Hassan y } \\
\text { Heweidi }^{16} \\
(2004)\end{array}$ & $\begin{array}{l}\text { Identificar las necesidades de las } \\
\text { familias jordanas de pacientes } \\
\text { críticamente enfermos }\end{array}$ & $\begin{array}{c}\text { 3 } \\
\text { (Observacional, } \\
\text { descriptivo, } \\
\text { transversal) }\end{array}$ & 158 & $\begin{array}{l}\text { CCFNI (Critical } \\
\text { Care Family Needs } \\
\text { Inventory) de } 45 \\
\text { ítems }\end{array}$ & $\begin{array}{l}\text { Mayor puntuación: necesidades } \\
\text { de seguridad, proximidad e in- } \\
\text { formación. Menor puntuación: } \\
\text { apoyo y confort. El más impor- } \\
\text { tante: hablar con el médico todos } \\
\text { los días. }\end{array}$ \\
\hline $\begin{array}{l}\text { Auerbach } \\
\text { y col }^{39} \\
(2005)\end{array}$ & $\begin{array}{l}\text { Valorar en los miembros de la fa- } \\
\text { milia al ingreso y al alta de UCI: la } \\
\text { satisfacción con las necesidades } \\
\text { cubiertas, signos y síntomas de } \\
\text { trastornos agudos de estrés, la } \\
\text { percepción sobre los profesio- } \\
\text { nales de la salud, el nivel de op- } \\
\text { timismo y la relación entre estas } \\
\text { variables }\end{array}$ & $\begin{array}{c}3 \\
\text { (Observacional, } \\
\text { comparativo, } \\
\text { transversal) }\end{array}$ & 40 & $\begin{array}{l}\text { CCFNI modificado } \\
\text { a } 14 \text { ítems }\end{array}$ & $\begin{array}{l}\text { Mayor puntuación: necesidades } \\
\text { de información y confort. El más } \\
\text { importante: tener claridad en las } \\
\text { explicaciones. Tendencia a una } \\
\text { mayor satisfacción de las necesi- } \\
\text { dades al alta. }\end{array}$ \\
\hline $\begin{array}{l}\text { Bijttebier } \\
\text { y col }^{41} \\
(2001)\end{array}$ & $\begin{array}{l}\text { Investigar las diferencias entre } \\
\text { las percepciones de los familia- } \\
\text { res, de los médicos y de las enfer- } \\
\text { meras sobre las necesidades de } \\
\text { los familiares de los pacientes de } \\
\text { cuidados críticos }\end{array}$ & $\begin{array}{c}\text { 3 } \\
\text { (Observacional, } \\
\text { descriptivo, } \\
\text { transversal) }\end{array}$ & 200 & CCFNI de 45 ítems & $\begin{array}{l}\text { Orden de puntuación: informa- } \\
\text { ción, seguridad, proximidad, apo- } \\
\text { yo y confort. El más importante: } \\
\text { que respondan a las preguntas } \\
\text { honestamente. }\end{array}$ \\
\hline $\begin{array}{l}\text { Burr }^{35} \\
(1998)\end{array}$ & $\begin{array}{l}\text { Obtener una comprensión más } \\
\text { global de las necesidades y de las } \\
\text { experiencias de los miembros de } \\
\text { la familia, así como profundizar } \\
\text { en los roles enfermera-familia y } \\
\text { en las relaciones desde la pers- } \\
\text { pectiva de las enfermeras de UCI }\end{array}$ & $\begin{array}{c}3 \\
\begin{array}{c}\text { (Triangulación } \\
\text { múltiple) }\end{array}\end{array}$ & 131 & CCFNI de 45 ítems & $\begin{array}{l}\text { Mayor puntuación: información, } \\
\text { seguridad y proximidad. Menor } \\
\text { puntuación: apoyo y confort. El } \\
\text { más importante: que respondan } \\
\text { a las preguntas honestamente. }\end{array}$ \\
\hline $\begin{array}{l}\text { Chien y } \\
\text { col }^{20} \\
(2006)\end{array}$ & $\begin{array}{l}\text { Examinar el efecto de un progra- } \\
\text { ma de educación basado en ne- } \\
\text { cesidades proporcionado en los } \\
\text { tres primeros días de hospitaliza- } \\
\text { ción del paciente, en los niveles } \\
\text { de ansiedad y en la satisfacción } \\
\text { de las necesidades psicosociales } \\
\text { de sus familias }\end{array}$ & $\begin{array}{c}2++ \\
\text { (Cuasi- } \\
\text { experimental) }\end{array}$ & $\begin{array}{l}34 \text { grupo } \\
\text { experimental } \\
32 \text { grupo } \\
\text { control }\end{array}$ & CCFNI de 45 ítems & $\begin{array}{l}\text { Mayor puntuación: información, } \\
\text { seguridad y apoyo. Menor pun- } \\
\text { tuación: proximidad y confort. El } \\
\text { más importante: conocer datos } \\
\text { específicos sobre el progreso del } \\
\text { paciente. }\end{array}$ \\
\hline $\begin{array}{l}\text { Damghi y } \\
\text { col }^{31} \\
(2008)\end{array}$ & $\begin{array}{l}\text { Evaluar la satisfacción de los } \\
\text { miembros de la familia y valorar } \\
\text { cuáles son sus determinantes en } \\
\text { una UCI de Marruecos utilizando } \\
\text { una clasificación y un método de } \\
\text { regresión }\end{array}$ & $\begin{array}{c}3 \\
\text { (Observacional, } \\
\text { descriptivo, } \\
\text { transversal) }\end{array}$ & 194 & $\begin{array}{l}\text { SCCMFNA (Society } \\
\text { of Critical Care } \\
\text { Medicine's Family } \\
\text { Needs Assessment) } \\
\text { de } 14 \text { ítems }\end{array}$ & $\begin{array}{l}\text { Orden de satisfacción de las } \\
\text { necesidades: actitud de los pro- } \\
\text { fesionales, comunicación, habi- } \\
\text { lidades de confort y soledad. La } \\
\text { necesidad mejor satisfecha: pen- } \\
\text { sar que se está dando el mejor } \\
\text { cuidado posible al paciente. }\end{array}$ \\
\hline $\begin{array}{l}\text { Dowling } y \\
\text { col }^{30} \\
(2005)\end{array}$ & $\begin{array}{l}\text { Validar el Family Satisfaction } \\
\text { Survey que es parte del Critical } \\
\text { Care Family Assistance Program } \\
\text { (CCFAP) }\end{array}$ & $\begin{array}{c}2+ \\
\text { (Ensayo no } \\
\text { controlado) }\end{array}$ & 330 & $\begin{array}{l}\text { Family Satisfaction } \\
\text { Survey }\end{array}$ & $\begin{array}{l}\text { Mayor satisfacción: manera en } \\
\text { la que los profesionales alivian } \\
\text { el dolor, la ansiedad y dejan } \\
\text { confortable al paciente. Menor } \\
\text { satisfacción: existencia de un } \\
\text { lugar privado en el hospital } \\
\text { para descansar. }\end{array}$ \\
\hline
\end{tabular}




\begin{tabular}{|c|c|c|c|c|c|}
\hline $\begin{array}{l}\text { Autor } \\
\text { (año) }\end{array}$ & Objetivo & $\begin{array}{c}\text { Tipo de estudio } \\
\text { y nivel de } \\
\text { evidencia }\end{array}$ & $\begin{array}{c}\text { Muestra de } \\
\text { familiares }\end{array}$ & $\begin{array}{c}\text { Cuestionario } \\
\text { utilizado para } \\
\text { valorar las } \\
\text { necesidades } \\
\end{array}$ & Resultados de interés \\
\hline $\begin{array}{l}\text { Freichels }{ }^{38} \\
\text { (1991) }\end{array}$ & $\begin{array}{l}\text { Comparar en dos intervalos de } \\
\text { tiempo en qué orden de impor- } \\
\text { tancia sitúan sus necesidades } \\
\text { los miembros de las familias con } \\
\text { allegados en la UCI }\end{array}$ & \begin{tabular}{|c|}
3 \\
(Observacional, \\
comparativo, \\
longitudinal)
\end{tabular} & 41 & $\begin{array}{l}\text { CCFNI modificado } \\
\text { a } 44 \text { ítems }\end{array}$ & $\begin{array}{l}\text { Orden de importancia de las } \\
\text { necesidades: seguridad, infor- } \\
\text { mación, proximidad, apoyo y } \\
\text { confort. El más importante: que } \\
\text { respondan a las preguntas hones- } \\
\text { tamente. }\end{array}$ \\
\hline $\begin{array}{l}\text { Heyland y } \\
\text { Tramer } \\
(2001)\end{array}$ & $\begin{array}{l}\text { Desarrollar un instrumento para } \\
\text { medir el nivel de satisfacción de } \\
\text { los miembros de las familias con } \\
\text { el cuidado recibido y el cuidado } \\
\text { proporcionado a su familiar críti- } \\
\text { camente enfermo }\end{array}$ & \begin{tabular}{|c|}
3 \\
(Observacional, \\
correlacional, \\
transversal)
\end{tabular} & 47 & $\begin{array}{l}\text { FS-ICU (Family } \\
\text { Satisfaction in the } \\
\text { Intensive Care } \\
\text { Unit) de } 34 \text { items }\end{array}$ & $\begin{array}{l}\text { Mayor satisfacción con la compe- } \\
\text { tencia y las habilidades de las en- } \\
\text { fermeras. Menor satisfacción con } \\
\text { la comunicación con el médico. }\end{array}$ \\
\hline $\begin{array}{l}\text { Heyland y } \\
\text { col }^{43} \\
(2002)\end{array}$ & $\begin{array}{l}\text { Determinar el nivel de satisfac- } \\
\text { ción de los miembros de la fa- } \\
\text { milia con el cuidado que reciben } \\
\text { ellos y sus familiares que están } \\
\text { en estado crítico }\end{array}$ & \begin{tabular}{|c|}
3 \\
(Observacional, \\
descriptivo, \\
transversal)
\end{tabular} & 624 & FS-ICU de 34 ítems & $\begin{array}{l}\text { Mayor satisfacción con la compe- } \\
\text { tencia y las habilidades de las en- } \\
\text { fermeras. Menor satisfacción con } \\
\text { el ambiente de la sala de espera. }\end{array}$ \\
\hline $\begin{array}{l}\text { Holden y } \\
\text { col }^{32} \\
(2002)\end{array}$ & $\begin{array}{l}\text { Abordar el tema de las familias } \\
\text { de los pacientes de cuidados } \\
\text { intensivos, explorando sus nece- } \\
\text { sidades y sus experiencias y res- } \\
\text { pondiendo a la pregunta: ¿Cómo } \\
\text { interactúan las enfermeras con } \\
\text { las familias de pacientes de UCI? }\end{array}$ & $\begin{array}{c}2- \\
\text { (Revisión } \\
\text { bibliográfica) }\end{array}$ & 40 artículos & $\begin{array}{l}\text { CCFNI en varias } \\
\text { versiones }\end{array}$ & $\begin{array}{l}\text { El cuestionario CCFNI falla al } \\
\text { mostrar la importancia de las in- } \\
\text { teracciones entre las enfermeras } \\
\text { y las familias. Aunque el desarro- } \\
\text { llo de una relación terapéutica } \\
\text { enfermera-familia requiera tiem- } \\
\text { po y energía, puede ayudar a re- } \\
\text { ducir el estrés. }\end{array}$ \\
\hline $\begin{array}{l}\text { Johnson y } \\
\text { col }^{5} \\
(1998)\end{array}$ & $\begin{array}{l}\text { Medir la capacidad para satisfa- } \\
\text { cer las necesidades familiares en } \\
\text { una UCI }\end{array}$ & \begin{tabular}{|c|}
3 \\
(Observacional, \\
descriptivo, \\
transversal) \\
\end{tabular} & 99 & $\begin{array}{l}\text { SCCMFNA de } 14 \\
\text { ítems }\end{array}$ & $\begin{array}{l}\text { Orden de satisfacción de las ne- } \\
\text { cesidades: comunicación, actitud } \\
\text { de los profesionales, habilidades } \\
\text { reconfortantes y soledad. }\end{array}$ \\
\hline $\begin{array}{l}\text { Kosco y } \\
\text { Warren }^{17} \\
(\mathbf{2 0 0 0 )}\end{array}$ & $\begin{array}{l}\text { Determinar si la percepción que } \\
\text { tienen las enfermeras de haber } \\
\text { satisfecho las necesidades de } \\
\text { las familias se corresponden con } \\
\text { las percepciones de las propias } \\
\text { familias }\end{array}$ & \begin{tabular}{|c|}
3 \\
(Observacional, \\
descriptivo, \\
transversal)
\end{tabular} & 45 & $\begin{array}{l}\text { CCFNI de } 45 \text { ítems } \\
\text { y NMI (Needs Met } \\
\text { Inventory) de } 45 \\
\text { ítems }\end{array}$ & $\begin{array}{l}\text { Mayor puntuación: seguridad, } \\
\text { información y proximidad. Me- } \\
\text { nor puntuación: apoyo y confort. } \\
\text { Orden de satisfacción de las ne- } \\
\text { cesidades: apoyo, proximidad, } \\
\text { información, seguridad y confort. } \\
\text { El más importante: conocer el } \\
\text { pronóstico del paciente. }\end{array}$ \\
\hline $\begin{array}{l}\text { Lee y } \operatorname{col}^{36} \\
(2000)\end{array}$ & $\begin{array}{l}\text { Valorar las necesidades más im- } \\
\text { portantes e inmediatas de los } \\
\text { miembros de las familias que } \\
\text { tienen un familiar ingresado en } \\
\text { el área de cuidados críticos en } \\
\text { Hong Kong }\end{array}$ & $\begin{array}{l}3 \\
\text { (Metodología } \\
\text { combinada } \\
\text { de tipo } \\
\text { explicatorio) }\end{array}$ & 30 & CCFNI de 45 ítems & $\begin{array}{l}\text { Mayor puntuación: seguridad e } \\
\text { información. Menor puntuación: } \\
\text { proximidad, apoyo y confort. El } \\
\text { más importante: conocer el re- } \\
\text { sultado esperado. }\end{array}$ \\
\hline $\begin{array}{l}\text { Lee y Lau }^{44} \\
(2003)\end{array}$ & $\begin{array}{l}\text { Investigar las necesidades inme- } \\
\text { diatas de los miembros de las } \\
\text { familias de pacientes adultos en } \\
\text { Hong Kong }\end{array}$ & \begin{tabular}{|c|}
3 \\
(Observacional, \\
descriptivo, \\
transversal)
\end{tabular} & 40 & CCFNI de 45 ítems & $\begin{array}{l}\text { Mayor puntuación: seguridad y } \\
\text { proximidad. Menor puntuación: } \\
\text { información, apoyo y confort. Or- } \\
\text { den de satisfacción de las nece- } \\
\text { sidades: seguridad, proximidad, } \\
\text { información, apoyo y confort. El } \\
\text { más importante: conocer el resul- } \\
\text { tado esperado. }\end{array}$ \\
\hline
\end{tabular}




\begin{tabular}{|c|c|c|c|c|c|}
\hline $\begin{array}{l}\text { Autor } \\
\text { (año) }\end{array}$ & Objetivo & $\begin{array}{c}\text { Tipo de estudio } \\
\text { y nivel de } \\
\text { evidencia }\end{array}$ & $\begin{array}{l}\text { Muestra de } \\
\text { familiares }\end{array}$ & $\begin{array}{c}\text { Cuestionario } \\
\text { utilizado para } \\
\text { valorar las } \\
\text { necesidades }\end{array}$ & Resultados de interés \\
\hline $\begin{array}{l}\text { Leung y } \\
\text { col }^{21} \\
(2000)\end{array}$ & $\begin{array}{l}\text { Identificar las percepciones que } \\
\text { tienen los miembros de las fami- } \\
\text { lias sobre sus necesidades inme- } \\
\text { diatas } 48-96 \text { h después del ingreso } \\
\text { de un familiar en una UCI en Hong } \\
\text { Kong y comparar esta percepción } \\
\text { con la percepción que tienen las } \\
\text { enfermeras de UCI sobre las nece- } \\
\text { sidades de las familias }\end{array}$ & $\begin{array}{c}3 \\
\text { (Observacional, } \\
\text { descriptivo, } \\
\text { transversal) }\end{array}$ & 37 & CCFNI de 45 ítems & $\begin{array}{l}\text { Mayor puntuación: seguridad e } \\
\text { información. Menor puntuación: } \\
\text { proximidad, apoyo y confort. El } \\
\text { más importante: que respondan } \\
\text { a las preguntas honestamente. }\end{array}$ \\
\hline $\begin{array}{l}\text { Leske }^{37} \\
(1991)\end{array}$ & $\begin{array}{l}\text { Estimar la fiabilidad y examinar } \\
\text { la validez de constructo de la } \\
\text { CCFNI }\end{array}$ & \begin{tabular}{|c|}
3 \\
(Observacional, \\
correlacional, \\
transversal) \\
\end{tabular} & 677 & CCFNI de 45 ítems & $\begin{array}{l}\text { Mayor puntuación: proximidad } \\
\text { y seguridad. El más importante: } \\
\text { sentir que hay esperanza. }\end{array}$ \\
\hline $\begin{array}{l}\text { Leske }^{11} \\
(1986)\end{array}$ & $\begin{array}{l}\text { Identificar las necesidades seña- } \\
\text { ladas por los miembros de las } \\
\text { familias de pacientes críticos }\end{array}$ & \begin{tabular}{|c}
3 \\
(Observacional, \\
descriptivo, \\
transversal) \\
\end{tabular} & 55 & CCFNI de 45 ítems & $\begin{array}{l}\text { Orden de importancia: seguri- } \\
\text { dad, información, proximidad, } \\
\text { confort y apoyo. El más impor- } \\
\text { tante: sentir que hay esperanza. }\end{array}$ \\
\hline $\begin{array}{l}\text { Maxwell y } \\
\text { col }^{45} \\
(2007)\end{array}$ & $\begin{array}{l}\text { Explorar las diferencias existen- } \\
\text { tes entre las percepciones de los } \\
\text { familiares de los pacientes críti- } \\
\text { cos y las de las enfermeras y de- } \\
\text { terminar la medida en que estas } \\
\text { necesidades fueron satisfechas }\end{array}$ & \begin{tabular}{|c|}
3 \\
(Observacional, \\
descriptivo, \\
transversal)
\end{tabular} & 20 & $\begin{array}{l}\text { CCFNI modificado } \\
\text { a } 30 \text { ítems y NMI } \\
\text { modificado a } 30 \\
\text { ítems }\end{array}$ & $\begin{array}{l}\text { Orden de importancia: seguri- } \\
\text { dad, información, proximidad y } \\
\text { apoyo. Orden de necesidades sa- } \\
\text { tisfechas: seguridad, información } \\
\text { y proximidad. El más importante: } \\
\text { que respondan a las preguntas } \\
\text { honestamente. La necesidad } \\
\text { mejor satisfecha: ver al paciente } \\
\text { frecuentemente. }\end{array}$ \\
\hline $\begin{array}{l}\text { Mendonca } \\
\text { y Warren } \\
\text { (1998) }\end{array}$ & $\begin{array}{l}\text { Valorar las percepciones de las } \\
\text { familias sobre el nivel de impor- } \\
\text { tancia de sus necesidades en las } \\
\text { primeras 18-24 horas después } \\
\text { del ingreso de un familiar en una } \\
\text { UCI e identificar qué necesidades } \\
\text { han sido satisfechas y cuáles no, } \\
\text { transcurridas } 36-48 \text { horas }\end{array}$ & $\begin{array}{c}3 \\
\text { (Observacional, } \\
\text { descriptivo, } \\
\text { transversal) }\end{array}$ & 52 & $\begin{array}{l}\text { CCFNI de } 45 \text { ítems } \\
\text { y NMI de } 45 \text { ítems }\end{array}$ & $\begin{array}{l}\text { Orden de importancia: seguri- } \\
\text { dad, información, proximidad, } \\
\text { apoyo y confort. El más impor- } \\
\text { tante: que le llamen a casa si hay } \\
\text { cambios en el estado del pacien- } \\
\text { te. Orden de necesidades satis- } \\
\text { fechas: seguridad, proximidad, } \\
\text { información, confort y apoyo. La } \\
\text { necesidad mejor satisfecha: ver } \\
\text { al paciente frecuentemente. }\end{array}$ \\
\hline $\begin{array}{l}\text { Molter }^{28} \\
(1979)\end{array}$ & $\begin{array}{l}\text { Responder a las siguientes pre- } \\
\text { guntas: ¿Qué necesidades per- } \\
\text { sonales identifican los familiares } \\
\text { de los pacientes críticos? ¿Cuál } \\
\text { es la importancia de estas nece- } \\
\text { sidades para los familiares? ¿Son } \\
\text { satisfechas esas necesidades, y si } \\
\text { lo son, por quién? }\end{array}$ & $\begin{array}{c}3 \\
\text { (Observacional, } \\
\text { descriptivo, } \\
\text { transversal) }\end{array}$ & 40 & CCFNI de 45 ítems & $\begin{array}{l}\text { Mayor puntuación: proximidad } \\
\text { y seguridad. El más importante: } \\
\text { sentir que hay esperanza. }\end{array}$ \\
\hline $\begin{array}{l}\text { Omari }^{46} \\
(2009)\end{array}$ & $\begin{array}{l}\text { Identificar las necesidades pro- } \\
\text { pias percibidas por los jordanos } \\
\text { adultos que tienen un familiar en } \\
\text { la UCI y explorar si esas necesida- } \\
\text { des se cubren }\end{array}$ & $\begin{array}{c}3 \\
\text { (Observacional, } \\
\text { descriptivo, } \\
\text { transversal) }\end{array}$ & 139 & $\begin{array}{l}\text { CCFNI de } 45 \text { ítems } \\
\text { y NMI de } 45 \text { ítems }\end{array}$ & $\begin{array}{l}\text { Orden de importancia: seguridad, } \\
\text { información, proximidad, confort } \\
\text { y apoyo. El más importante: estar } \\
\text { seguro de que se está dando al } \\
\text { paciente el mejor cuidado posi- } \\
\text { ble. Orden de necesidades satis- } \\
\text { fechas: seguridad, proximidad, } \\
\text { confort, apoyo e información. La } \\
\text { necesidad mejor satisfecha: tener } \\
\text { alguien que se preocupa de su } \\
\text { salud. }\end{array}$ \\
\hline
\end{tabular}




\begin{tabular}{|c|c|c|c|c|c|}
\hline $\begin{array}{l}\text { Autor } \\
\text { (año) }\end{array}$ & Objetivo & $\begin{array}{c}\text { Tipo de estudio } \\
\text { y nivel de } \\
\text { evidencia }\end{array}$ & $\begin{array}{c}\text { Muestra de } \\
\text { familiares }\end{array}$ & $\begin{array}{c}\text { Cuestionario } \\
\text { utilizado para } \\
\text { valorar las } \\
\text { necesidades }\end{array}$ & Resultados de interés \\
\hline $\begin{array}{l}\text { Paul y } \\
\text { Rattray }^{33} \\
(\mathbf{2 0 0 8 )}\end{array}$ & $\begin{array}{l}\text { Identificar el impacto que tiene } \\
\text { una enfermedad crítica en los } \\
\text { familiares a corto y a largo plazo }\end{array}$ & $\begin{array}{c}2+ \\
\text { (Revisión } \\
\text { bibliográfica) }\end{array}$ & 80 artículos & $\begin{array}{l}\text { CCFNI en varias } \\
\text { versiones }\end{array}$ & $\begin{array}{l}\text { A pesar de que el cuestionario } \\
\text { CCFNI ha contribuido al conoci- } \\
\text { miento de las necesidades de los } \\
\text { familiares y ha sido aplicado en } \\
\text { múltiples estudios, hay algunas } \\
\text { necesidades (sobre todo psico- } \\
\text { lógicas) que no son identificadas }\end{array}$ \\
\hline $\begin{array}{l}\text { Santana } \\
\text { Freitas y } \\
\text { col }^{40} \\
(2007)\end{array}$ & $\begin{array}{l}\text { Comparar el grado de impor- } \\
\text { tancia y la satisfacción de las } \\
\text { necesidades de los familiares de } \\
\text { pacientes adultos ingresados en } \\
\text { la UCI de un hospital público y en } \\
\text { uno privado }\end{array}$ & \begin{tabular}{|c|}
3 \\
(Observacional, \\
comparativo, \\
transversal)
\end{tabular} & 91 & CCFNI de 43 ítems & $\begin{array}{l}\text { Orden de importancia: seguri } \\
\text { dad, información, proximidad, } \\
\text { confort y apoyo. El más impor- } \\
\text { tante: estar seguro de que se está } \\
\text { dando al paciente el mejor cuida- } \\
\text { do posible. }\end{array}$ \\
\hline $\begin{array}{l}\text { Stricker y } \\
\text { col }^{47} \\
(2009)\end{array}$ & $\begin{array}{l}\text { Valorar la satisfacción de la fami- } \\
\text { lia en la UCI e identificar paráme- } \\
\text { tros para mejorar }\end{array}$ & \begin{tabular}{|c|}
3 \\
(Observacional, \\
descriptivo, \\
transversal) \\
\end{tabular} & 996 & $\begin{array}{l}\text { FS-ICU modificado } \\
\text { a } 24 \text { ítems }\end{array}$ & $\begin{array}{l}\text { No presenta tablas; difícil valorar } \\
\text { resultados. }\end{array}$ \\
\hline $\begin{array}{l}\text { Verhaeghe } \\
\text { y col }^{34} \\
(2005)\end{array}$ & $\begin{array}{l}\text { Estructurar el conocimiento } \\
\text { científico disponible sobre las } \\
\text { necesidades y las experiencias } \\
\text { de los familiares de pacientes de } \\
\text { cuidados intensivos }\end{array}$ & $\begin{array}{c}2+ \\
\text { (Revisión } \\
\text { bibliográfica) }\end{array}$ & 46 artículos & $\begin{array}{l}\text { CCFNI en varias } \\
\text { versiones }\end{array}$ & $\begin{array}{l}\text { Dividen los ítems del CCFNI en } \\
4 \text { categorías: necesidades cog } \\
\text { nitivas, emocionales, sociales y } \\
\text { prácticas basándose en varios } \\
\text { estudios. Señalan la importancia } \\
\text { de utilizar métodos cualitativos } \\
\text { para ampliar el enfoque y encon- } \\
\text { trar otras necesidades. }\end{array}$ \\
\hline $\begin{array}{l}\text { Wall y } \\
\text { col }^{48} \\
(2007)\end{array}$ & $\begin{array}{l}\text { Identificar aspectos específicos } \\
\text { del cuidado que son calificados } \\
\text { más altamente por los miembros } \\
\text { de la familia de los pacientes } \\
\text { fallecidos en la UCI en compara- } \\
\text { ción con los familiares de los pa- } \\
\text { cientes supervivientes de la UCI }\end{array}$ & \begin{tabular}{|c|}
3 \\
(Observacional, \\
descriptivo, \\
transversal)
\end{tabular} & 539 & $\begin{array}{l}\text { FS-ICU modificado } \\
\text { a } 24 \text { ítems }\end{array}$ & $\begin{array}{l}\text { Mayor satisfacción con: sentirse } \\
\text { incluido en la toma de decisio- } \\
\text { nes. Menor satisfacción con: el } \\
\text { ambiente en la sala de espera. }\end{array}$ \\
\hline $\begin{array}{l}\text { Wall y } \\
\text { col }^{49} \\
(2007)\end{array}$ & $\begin{array}{l}\text { Refinar el cuestionario FS-ICU y } \\
\text { desarrollar un método validado } \\
\text { para puntuar el instrumento }\end{array}$ & \begin{tabular}{|c|}
3 \\
(Observacional, \\
descriptivo, \\
transversal)
\end{tabular} & 1038 & FS-ICU de 34 ítems & $\begin{array}{l}\text { Mayor satisfacción con: la com- } \\
\text { petencia y las habilidades de las } \\
\text { enfermeras. Menor satisfacción } \\
\text { con: el ambiente en la sala de } \\
\text { espera. }\end{array}$ \\
\hline $\begin{array}{l}\text { Warren }^{50} \\
\text { (1993) }\end{array}$ & $\begin{array}{l}\text { Describir las necesidades perci- } \\
\text { bidas por los familiares durante } \\
\text { las primeras 18-24horas después } \\
\text { del ingreso del paciente en la UCI }\end{array}$ & \begin{tabular}{|c|}
3 \\
(Observacional, \\
descriptivo, \\
transversal)
\end{tabular} & 94 & $\begin{array}{l}\text { CCFNI de } 45 \text { ítems } \\
\text { y NMI de } 45 \text { ítems }\end{array}$ & $\begin{array}{l}\text { Orden importancia: seguridad, } \\
\text { información, proximidad, apoyo } \\
\text { y confort. Orden se necesidades } \\
\text { satisfechas: seguridad, apoyo, } \\
\text { confort, proximidad e informa- } \\
\text { ción. }\end{array}$ \\
\hline $\begin{array}{l}\text { Wasser y } \\
\text { col }^{31} \\
(2001)\end{array}$ & $\begin{array}{l}\text { Desarrollar y validar la encuesta } \\
\text { Critical Care Family Satisfaction } \\
\text { Survey como indicador de la sa- } \\
\text { tisfacción del paciente }\end{array}$ & \begin{tabular}{|c|}
3 \\
(Observacional, \\
correlacional, \\
transversal)
\end{tabular} & 237 & $\begin{array}{l}\text { CCFSS (Critical } \\
\text { Care Family Satis- } \\
\text { faction Survey) de } \\
20 \text { ítems }\end{array}$ & $\begin{array}{l}\text { Aporta datos sobre el desarro- } \\
\text { llo, la fiabilidad y la validez del } \\
\text { instrumento pero no describe } \\
\text { cuáles son las respuestas de los } \\
\text { participantes. }\end{array}$ \\
\hline
\end{tabular}


El cuestionario FS-ICU ha sido utilizado en estudios descriptivos por Heyland y colaboradores ${ }^{43}$ utilizando una muestra de 624 participantes y por Wall y col ${ }^{49}$ con 1.038 familiares. De una manera similar, Stricker y col$^{47}$ y Wall y col ${ }^{48}$, han utilizado una versión modificada, refinada y validada de 24 ítems con las mismas subescalas. Aunque se trata de un instrumento de calidad y aplicable en el contexto de cuidados críticos, tras valorar las necesidades que pretende explorar, se podría decir que no contempla necesidades que son consideradas de gran importancia por las familias como las de seguridad, proximidad o apoyo. En todo caso, y teniendo en cuenta que evalúa la satisfacción de los clientes, sería recomendable revalorar las respuestas de los familiares tras haber introducido intervenciones para cubrir las necesidades detectadas y así se podría comparar si realmente ha mejorado la satisfacción de las familias en cuanto a sus necesidades percibidas.

Siguiendo con la revisión de los distintos instrumentos, tras su creación por la Society of Critical Care Medicine y su posterior modificación por Johnson y $\mathrm{col}^{5}$, el cuestionario SCCMFNA ha sido utilizado por Damghi y $\operatorname{col}^{42}$, una vez traducido al árabe (siguiendo las recomendaciones de las guías internacionales) con 194 participantes en un estudio descriptivo. En este caso, el cuestionario, va dirigido sobre todo a indagar en las necesidades de información, apoyo y confort y en las cualidades de los profesionales. Este cuestionario resulta ser algo superficial en lo que se refiere a la valoración de las necesidades de los familiares como personas en una situación extraordinaria, porque no profundiza en sus percepciones ni en sus sentimientos respecto al momento que viven.

Por otra parte, el estudio de Dowling y col $^{30}$, desarrollado entre los años 2002 y 2004, fue el encargado de desarrollar el instrumento Family Satisfaction Survey. Esta herramienta es parte del programa Critical Care Family Assistance Program (CCFAP) implantado en seis hospitales estadounidenses. El objetivo de este programa es responder a las necesidades no satisfechas de las familias de pacientes ingresados en la UCI a través de la provisión de recursos educativos y de apoyo familiar. Este estudio es un ensayo no controlado, puesto que compara los resultados del cuestionario en la misma muestra antes y después de implantar un programa de educación. Tras la lectura del objetivo del mencionado programa, resultaría de gran interés poder estudiarlo e incluso aplicarlo en otros centros, pero al no estar descritas en el texto las características del programa, resulta difícil valorar la relevancia y la aplicabilidad del mismo.

Por último está el cuestionario CCFSS creado por Wasser y col $^{31}$ en un estudio correlacional. La herramienta incluye las categorías de necesidades descritas por autores como Leske ${ }^{9}$ que son las de apoyo, confort, información, proximidad y seguridad. Sin embargo, tras la revisión de todos los apartados de la escala, se puede determinar que los aspectos valorados van más dirigidos a la visión del familiar respecto a lo que rodea al paciente que a lo que concierne a sus propios requerimientos como persona allegada.

\section{DISCUSIÓN}

A través de esta revisión, se ha podido conocer la existencia de cinco cuestionarios utilizados para valorar las necesidades de los familiares de pacientes ingresados en UCI. Estos son el CCFNI, FS-ICU, SCCMFNA, Family Satisfaction Survey y CCFSS. Atendiendo a las características analizadas de cada uno de ellos, resulta difícil recomendar un único cuestionario y sugerir su aplicación de manera estandarizada, puesto que todos ellos tienen adecuados niveles de validez y fiabilidad. Cabe sin embargo señalar que, atendiendo a las áreas que estudia cada cuestionario, no hemos encontrado uno que englobe toda la variabilidad de categorías de necesidades que son susceptibles de ser exploradas.

Con respecto a las características de los estudios incluidos en esta revisión sistemática, destacamos que la mayoría son de carácter descriptivo, por lo que el conocimiento que aportan no añade nuevos 
resultados, al existir numerosos estudios que exploran cuáles son las necesidades de los familiares. Por tanto, al haber pocos estudios $^{20,32}$ que utilizan una metodología experimental, resulta difícil sugerir estrategias que mejoren la experiencia de los familiares $^{32}$. Además, la mayoría de los estudios están basados en el cuestionario CCFNI, de amplia difusión y reconocida validez, y esto puede dar una visión limitada de las necesidades existentes, ya que hay áreas que quedan sin explorar como: las actividades de la vida diaria, la interacción con los profesionales o la preocupación por el resto de los familiares, aunque sigue siendo el cuestionario que más profundiza en las experiencias de la familia. Los demás cuestionarios revisados, parecen tener importantes restricciones a la hora de valorar íntegramente a la familia, sobre todo en lo referente al apoyo social y a las necesidades emocionales, porque se centran más en las actitudes de los profesionales y en la satisfacción con el cuidado del paciente.

En otro sentido, el enfoque cuantitativo existente en múltiples investigaciones puede estar ligado a la visión positivista tradicional que asume que las mediciones sistemáticas pueden producir una evidencia generalizable a entornos similares. ${ }^{32} \mathrm{Sin}$ embargo, algunos estudios ${ }^{11,17,20-22,28,29,36-39,44}$ utilizan muestras pequeñas de conveniencia que pueden limitar la extrapolación de los resultados y en todo caso, todas las publicaciones revisadas se podrían criticar por aportar una perspectiva rígida y poco holística del cuidado a la familia, siendo aplicados únicamente a uno de los familiares. Para evitar estas limitaciones, autores como Burr ${ }^{35}$, Lee y col ${ }^{36}$ o Verhaeghe y col ${ }^{34}$, abogan por utilizar una combinación de metodologías, que incluye métodos cualitativos y cuantitativos en la recogida de datos y en el análisis, y que pretende obtener un entendimiento más global de las necesidades y experiencias de los familiares. Chien y colaboradores ${ }^{20}$ por su lado, defienden el beneficio de los programas educativos basados en las necesidades concretas de los familiares y Holden y colaboradores $^{32}$ dicen que la investigación en acción sería muy útil para evaluar interven- ciones focalizadas en la participación de la familia en la UCI.

Por otro lado, está surgiendo un creciente interés por formar a los equipos multidisciplinares en aspectos para satisfacer las necesidades de los familiares, modos de aumentar la satisfacción con el cuidado, cómo mejorar la comunicación e incluso en la incorporación de modelos de atención estandarizados centrados en la familia $^{30}$. Es más, algunos autores defienden la implantación de un enfoque de atención familiar que pueda dar respuesta tanto a las necesidades del paciente como a las de su familia ${ }^{6}$. Una de las razones de este cambio es que se ha asumido que el estado de la familia tiene efectos en el bienestar y en la recuperación del paciente ${ }^{17}$ y que un cuidado integral de la persona debe incluir también a su entorno más próximo. De hecho, tal y como indica Yurss ${ }^{51}$, recientemente han aparecido un conjunto de estudios experimentales con control aleatorio que refuerzan la hipótesis de que la familia influye en la salud de sus miembros y que confirman la necesidad de una estrecha colaboración entre el profesional sanitario, el paciente y su familia para obtener una atención sanitaria más eficaz.

Por todo ello, parece estar justificada la necesidad de desarrollar métodos innovadores para valorar y satisfacer las necesidades de estos familiares. Recomendamos realizar, en una primera fase, un estudio cualitativo que identifique las necesidades reales de las familias mediante entrevistas y posteriormente validar las necesidades identificadas en forma de cuestionario. Éste se debería adecuar a la presente situación socio-económico-demográfica y a las demandas actuales de las familias e incluir preguntas abiertas que permitan profundizar más en las experiencias familiares. Una vez realizada la valoración familiar, se deberían llevar a cabo intervenciones para satisfacer esas necesidades y adelantarse a ellas. Además, es necesario investigar sobre la efectividad de dichas intervenciones y así poder crear planes de atención estandarizados y flexibles en las UCI.

En el área asistencial, un estudio con estas dimensiones podría aportar herra- 
mientas válidas y fiables para valorar a las familias y así se podrían aplicar planes de actuación adaptados a las necesidades detectadas. Del mismo modo, las experiencias de los familiares podrían servir de guía para detectar lagunas en la atención, que podrían corregirse mediante programas de formación continuada. Para concluir, creemos que una atención centrada en la familia como unidad, resultaría de gran interés para el área de la gestión, puesto que aseguraría un cuidado individualizado, holístico y de calidad para toda la familia, consiguiendo así la satisfacción de los clientes y de los profesionales.

\section{BIBLIOGRAFÍA}

1. Hughes F, Bryan K, RobBins I. Relatives experiences of critical care. Nurs Crit Care 2005; $10: 23-30$.

2. Myhren H, Ekeberg O, Langen I, Stokland O. Emotional strain, communication, and satisfaction of family members in the intensive care unit compared with expectations of the medical staff: experiences from a Norwegian University Hospital. Intensive Care Med 2004; 30: 1791-1798.

3. Pochard F, Darmon M, Fassier T, et al. Symptoms of anxiety and depression in family members of intensive care unit patients before discharge or death. A prospective multicenter study. J Crit Care 2005; 20: 90-96.

4. Coulter MA. The needs of family members of patients in intensive care unit. Intensive Care Nurs 1989; 5: 4-10.

5. Johnson D, Wilson M, Cavanaugh B, Bryden C, Gudmundson D, Moodley O. Measuring the ability to meet family needs in an intensive care unit. Crit Care Med 1998; 26 : 266-271.

6. FuERTES MC, MAYA MU. Atención a la familia: la atención familiar en situaciones concretas. An Sist Sanit Navar 2001; 24 : 83-92.

7. MARTín A, PÉrez MA. Psychosocial adaptation in relatives of critically injured patients admitted to an intensive care unit. Span J Psychol 2005; 8: 36-44.

8. Alvarez GF, Kirby AS. The perspective of families of the critically ill patient: their needs. Curr Oping Crit Care 2006; 12: 614-618.

9. LESKE JS. Overview of family needs after critical illness: From assessment to intervention. AACN Clinical Issues 1991; 2 : 220-228.
10. Pardavila Belio Mi, Vivar CG. Necesidades de la familia en las unidades de cuidados intensivos. Revisión de la literatura. Enferm Intensiva 2011; doi:10.1016/j.enfi.2011.06.001.

11. LESKE JS. Needs of relatives of critically ill patients: A follow up. Heart Lung 1986; 15: 189193.

12. Quinn S, Redmond K, Begley C. The needs of relatives visiting audit critical care units as perceived by relatives and nurses. Parts 1 \& 2. Intensive Crit Care Nurs. 1996; 12: 168-172 \& 12: 239-245.

13. GELLING L. Causes of ICU psychosis: the environmental factors. Nurs Crit Care 1999 ; 4 : 2226.

14. Vosburgh D, Simpson P. Linking family theory and practice: a family nursing program. J Nurs Scholarsh 1993; 25: 231-235.

15. Wesson JS. Meeting the informational, psychosocial and emotional needs of each ICU patient and family. Intensive Crit Care Nurs 1997; 13: 111-118.

16. Al-Hassan MA, Hweidi IM. The perceived needs of Jordanian families of hospitalized critically ill patients. Int J Nurs Pract 2004; 10: 6471.

17. Kosco M, Warren NA. Critical care nurses' perceptions of family needs as met. Crit Care Nurs Q 2002; 23: 60-72.

18. Neabel B, Fothergill-Bourbonnais F, Dunning J. Family assessment tools: A review of the literature from 1978-1997. Heart Lung 2000; 29: 196-209.

19. HaRTRICK G, LindSEy AE, Hills M. Family nursing assessment: meeting the challenge of health promotion. J Adv Nurs 1994; 20: 85-91.

20. Chien WT, ChiU YL, LAM LW, Ip WY. Effects of a needs-based education programme for family carers with a relative in an intensive care unit: A quasi-experimental study. Int J Nurs Stud 2006; 43: 39-50.

21. Leung KK, Chien WT, Mackenzie AE. Needs of Chinese families of critically ill patients. Western J Nurs Res 2000; 22: 826-840.

22. Mendonca D, Warren NA. Perceived and unmet needs of critical care family members. Crit Care Nurs Q 1998; 21: 58-68.

23. Holopainen A, HaKulinen-Vittanen T, Tossavainen K. Systematic review- a method for nursing research. Nurse Res 2008; 16: 72-83.

24. Straus SE, Glasziou P, Richardson WS, Haynes RB. Evidence-based medicine. How to practice and teach EBM. 3rd ed.: Edinburgh: Churchill Livingston, 2005; 13-30. 
25. Scottish Intercollegiate Guidelines Network. A guideline developer's handbook. 2008. Disponible en: http://www.sign.ac.uk/pdf/ sign50.pdf

26. Critical Appraisal Skills Programme Español. 11 preguntas para entender un ensayo clínico y 10 preguntas para ayudarte a entender una revisión. Disponible en: http://www.redcaspe.org/que-hacemos/herramientas/

27. Berra S, Elorza-Ricart JM, Estrada MD, SÁNCHEZ E. Instrumento para la lectura crítica y la evaluación de estudios epidemiológicos transversales. Gac Sanit 2008; 22: 492-497.

28. Molter NC. Needs of relatives of critically ill patients: A descriptive study. Heart Lung 1979; 8: 332-339.

29. Heyland DK, Tranmer J. Measuring family satisfaction with care in the intensive care unit: the development of a questionnaire and preliminary results. J Crit Care 2001; 16: 142-149.

30. Dowling J, Vender J, Guilianelli S, Wang B. A Model of family-centered care and satisfaction predictors: the Critical Care Family Assistance Program. Chest 2005; 128: 81S-92S.

31. Wasser T, Pasquale MA, Matchett SC, Bryan Y, PAsquale M. Establishing reliability and validity of the Critical Care Family Satisfaction Survey. Crit Care Med 2001; 29: 192-196.

32. Holden J, Harrison L, Johnson M. Families, nurses and intensive care patients: a review of the literature. J Clin Nurs 2002; 11: 140-148.

33. Paul F, Ratray J. Short- and long-term impact of critical illness on relatives: literature review. J Adv Nurs 2008; 62: 276-292.

34. Verhaeghe S, Defloor T, Van Zuuren F, Duijnstee M, GRYPdonck M. The needs and experiences of family members of adult patients in an intensive care unit: a review of the literature. J Clin Nurs 2005; 14: 501-509.

35. BuRR G. Contextualizing critical care family needs through triangulation: an Australian study. Intensive Crit Care Nurs 1998; 14: 161169.

36. Lee IYM, Chien WT, Mackenzie A. Needs of families with a relative in a critical care unit in Hong Kong. J Clin Nurs 2000; 9: 46-54.

37. LESKE JS. Internal psychometric properties of the critical care family needs inventory. Heart \& Lung 1991; 20: 236-244.

38. Freichels TA. Needs of family members of patients in the intensive care unit over time. Crit Care Nurs Q 1991; 14: 16-29.

39. Auerbach SM, Kiesler DJ, Wartella J, Rausch S, WARD KR, IVATURY R. Optimism, satisfaction with needs met, interpersonal perceptions of the healthcare team, and emotional distress in patients' family members during critical care hospitalization. Am J Crit Care 2005; 14 : 202-210.

40. Santana Freitas K, Kimura M, São Leão FerreiRA KA. Family members' needs at intensive care units: comparative analysis between a public and a private hospital. Revista Latinoamericana Enfermagem 2007; 15: 84-92.

41. Bijttebier P, Vanoost S, Delva D, Ferdinande P, FRANS E. Needs of relatives of critical care patients: perceptions of relatives, physicians and nurses. Intensive Care Med 2001; 27: 160165.

42. Damghi N, Khoudri I, Oualili L, Abidi K, Madani N, Ali Zeggwagh A, Abouqal R. Measuring the satisfaction of intensive care unit patient families in Morocco: A regression tree analysis. Crit Care Med 2008; 36: 2084-2091.

43. Heyland DK, Rocker GM, Dodeck PM, Kutsogiannis DJ, Konopad E, Cook DJ, Peters S, Tranmer JE, O'Callaghan CJ. Family satisfaction with care in the intensive care unit: Results of the multiple center study. Crit Care Med 2002; 30: 1413-1418.

44. LEE LYK, LAU YL. Immediate needs of adult family members of adult intensive care patients in Hong Kong. J Clin Nurs 2003; 12: 490500 .

45. Maxwell KE, Stuenkel D, Saylor C. Needs of family members of critically ill patients: A comparison of nurse and family perceptions. Heart Lung 2007; 36: 367-376.

46. Omari FH. Perceived and Unmet Needs of Adult Jordanian Family Members of Patients in ICUs. J Nurs Scholarsh 2009; 41: 28-34.

47. Stricker KH, Kimberger O, Schmidlin K, Zwahlen M, Mohr U, Rothen HU. Family satisfaction in the intensive care unit: what makes the difference? Intensive Care Med 2009; 35: 20512059.

48. Wall RJ, Curtis R, Cooke CR, Engelberg RA. Family satisfaction in the ICU: Differences between families of survivors and nonsurvivors. Chest 2007; 132: 1425-1433.

49. Wall RJ, Engelberg RA, Downey L, Heyland DK, CURTIS JR. Refinement, scoring, and validation of the Family Satisfaction in the Intensive Care Unit (FS-ICU) survey. Crit Care Med 2007; 35: 271-279.

50. WARREN NA. Perceived needs of the family members in the critical care waiting room. Crit Care Nurs Q 1993; 16: 56-63.

51. YuRss I. Atención a la familia: otra forma de enfocar los problemas de salud en atención primaria. Instrumentos de abordaje familiar. An Sist Sanit Navar 2001; 24: 73-82. 
